\title{
Using Transnational Online Learning Experiences for Building International Student Working Groups and Developing Intercultural Competences
}

\author{
Mr. Dominik May, TU Dortmund University
}

Dominik May holds a degree in Industrial Engineering from TU Dortmund University (Germany). Currently he is a research associate and doctoral candidate at the Center for Higher Education at TU Dortmund University in the area of engineering education research. In his position he is managing several research and development projects on engineering education and technical training. Furthermore he offers workshops on professional teaching and learning for engineering faculty. In his research Dominik May focuses, inter alia, on future requirements for science and engineering graduates, such as international competence, in order to become successful engineers in a globalized professional world. Therefore he designs and investigates respective educational strategies with a special focus on online solutions and the integration of remote laboratories. For his research and the development of several transnational online courses he benefits from his working experience in international companies and a broad international professional network. Furthermore Dominik May is founding member of both the Engineering Education Research Group at the Center for Higher Education and the Working Group for Engineering Education at the German Society for Higher Education (dghd).

\section{Prof. A. Erman Tekkaya, TU Dortmund University}

Since 2007, A. Erman Tekkaya is Professor at the TU Dortmund University and Head of the Institute of Forming Technology and Lightweight Construction (IUL). Since 2011 he is senior coordinator of the MMT degree program, the Master of Science in Manufacturing Technology. Since October 2014 he is also Dean of the Faculty of Mechanical Engineering. A. Erman Tekkaya studied mechanical engineering at the Department of Mechanical Engineering at the Middle East Technical University in Ankara. He finished his PhD in 1985, at the Institute for Metal Forming Technology at University of Stuttgart, with honors. In 1988, the Habilitation (Üniversite docenti) at the TC Üniversite-ler Arası Kurul in Ankara followed. From 1986 to 2005 he worked at the Middle East Technical University in Ankara. After his time as Assistant and Associate Professor he became Full Professor in 1993. From 2005 to 2009 A. Erman Tekkaya was Professor and Head of the Manufacturing Engineering Department at the ATILIM University in Ankara. Until September 2013 he was the founding director of the Center of Excellence on Metal Forming in Ankara. His research interests are metal forming technologies as bulk metal forming, sheet metal forming, bending and high speed forming, as also the modeling of metal forming processes and material characterization. In recognition of his contributions in the field of metal forming he was awarded the honorary degree Doktor-Ingenieur Ehren halber (Dr.-Ing. E.h.) by the Faculty of Engineering of Friedrich-Alexander-Universität in Erlangen-Nürnberg in 2012. In October 2014 he was awarded the International Prize for Research \& Development in Precision Forging of the Japanese Society of Technology of Plasticity for process innovation, process characterization and international Leadership. A. Erman Tekkaya is member of numerous national and international committees and cherishes memberships to national and international scientific academies and associations. A. Erman Tekkaya is "Editor-in-Chief" of the Journal of Materials Processing Technology of Elsevier for 9 years. 


\title{
Using transnational online learning experiences for building in- ternational student working groups and developing intercultural competences
}

\author{
Dominik May, Center for Higher Education, TU Dortmund University, Germany \\ A. Erman Tekkaya, Institute of Forming Technology and Lightweight Construction, TU \\ Dortmund University, Germany
}

\section{Introduction and context}

In the $21^{\text {st }}$ century the development of intercultural awareness and intercultural competence is more important than ever ${ }^{1}$. Thereby it is becoming a more and more important task in higher education, too. The world is, especially in the professional context of engineering, much more globally connected than ever before, which applies to the economical as well as to the educational sector. Hence, one main task for higher engineering education is to prepare the students for these international labor markets in the best possible way. Developing the respective competences can be done through several different approaches. The most common, and maybe the most effective way, is to spend some time abroad for an international internship or for studying in a foreign country. Programs and opportunities to study abroad are nearly uncountable. For example, during winter term $2014 / 15$ over 300,000 international students studied in Germany and during the year 2013 over 130,000 German students went abroad to gain new international experiences ${ }^{2,3}$. International study programs, in which students spend a whole course of studies in a foreign country (instead of only some months), are a special opportunity to gain international insights. The engineering faculty at TU Dortmund University in Germany offers such a master program starting every October, the international "Master of Science in Manufacturing Technology (MMT)". The Institute of Forming and Lightweight Construction (IUL) mainly organizes this program. It offers a compact 2-year English taught program to attract engineering students from all around the world. The MMT comprises theoretical fundamentals in machining, materials, and forming technology - interlaced with comprehensively applied hands-on science studies. Students are given the opportunity to carry out their hands-on experiments alongside with researchers in highly equipped labs. The concluding master thesis should be done with leading companies in the sector of manufacturing technology.

In order to prepare the MMT students for their time in Germany and based on our lessons learned from recent years, we decided to develop a special online course, which is provided before the students leave their home country for their stay in Germany. In addition to the students' preparation for their stay at TU Dortmund University the above mentioned necessity to prepare students for a global working environment was an important issue leading into the realization of this course. Apart from the possibility to develop respective competences during overseas stays we see great potentials in the use of online technology for building transnational student working groups and by this designing international as well as intercultural learning environments. The developed online course is an example how to design such courses with respect to both intercultural and technical competence development as equal course objectives.

In summer 2014, the preparatory online course was delivered for the first time in a 3-week format. An updated second 4-week course was held in 2015. The evaluation results presented in this paper are primarily based on the second round results. In the following, the course 
concept will be described more in detail. Afterwards, we will explain the evaluation concept we intentionally designed for this course, discuss the evaluation results and will end with a final summary.

\section{Course concept}

The course concept is based on two core course objectives and three instructional tools for course delivery and interaction (see figure 1). We will start by explaining the course objectives first, followed by a review of the instructional resources.

On the one hand the course aims for preparing students for their time in Germany. Based on our and the students' reported experiences from earlier MMT cohorts, the students basically struggle with very practical difficulties when they arrive in Germany. Among these difficulties, there are aspects like cultural and academic habits, housing, or enrollment in lectures. The students, who sign up for the MMT program, come from all over the world. They all have different cultural backgrounds and are used to study in different educational systems with different methods of teaching. Hence, the idea was to bring them into contact with the educational culture and concepts they will be facing during their future studies here at the TU Dortmund University. In addition to that we tried to present the future place of living for the students.

The second course objective, and this will be the more important one for this paper, is about preparing the students for a professional life in a globalized world. All of the participating

\section{course objectives}

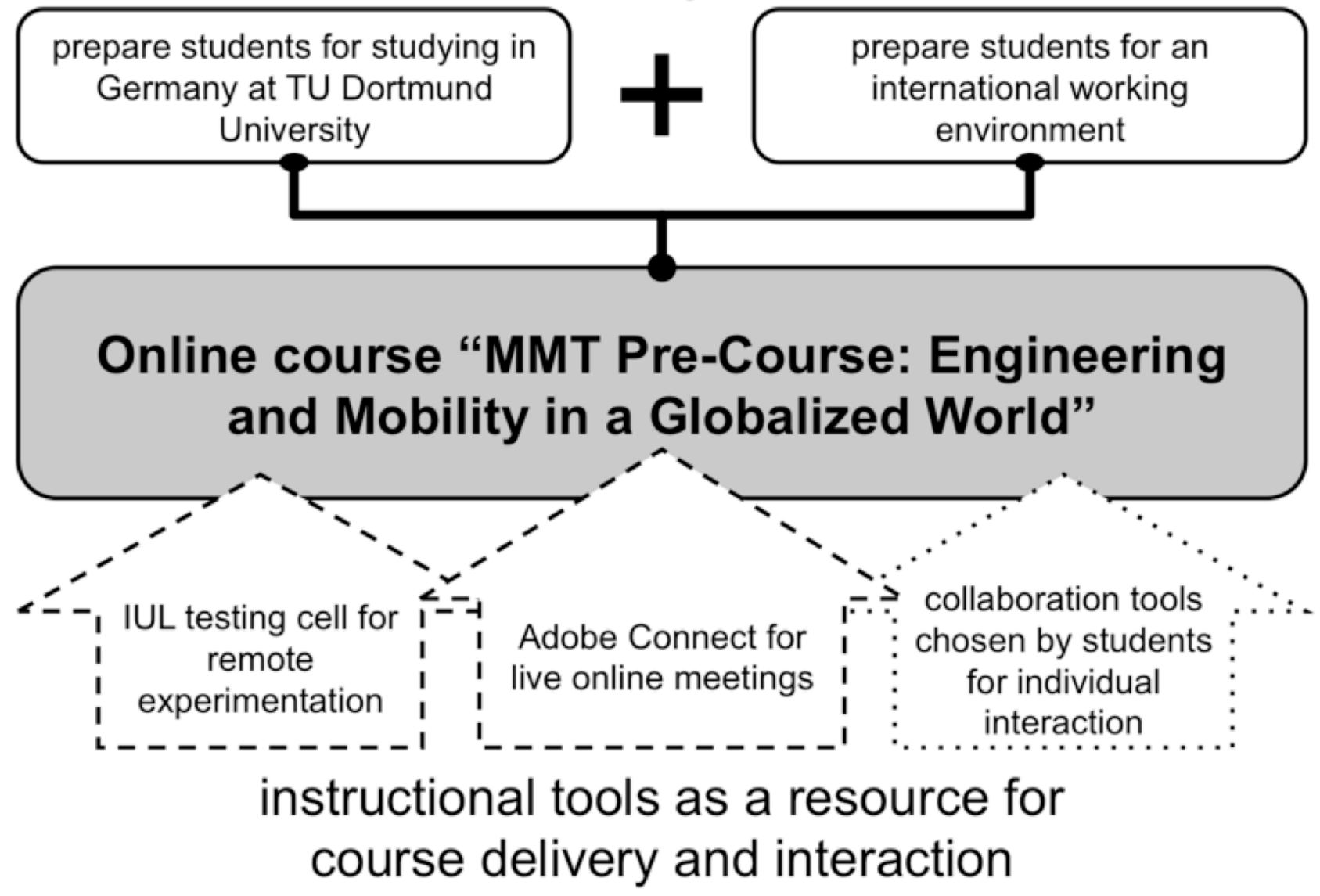

Figure 1: Concept for MMT pre-course based on two objectives and three instructional tools 
students will start to work as engineers after their master program, either in the industry or in the academia. The ability to effectively collaborate in professional and transnational settings is more important than ever. Hence, the students are expected to develop real intercultural competences, ideally already during their studies. Without going too much in detail about the notion of intercultural competence itself, the following definition posed by D.K. Deardorff should serve as working definition for our context ${ }^{1}$ :

\section{"Intercultural competence describes the ability to effectively and adequately in- teract in intercultural situations based on explicit attitudes as well as the special ability to act and reflect." "(own translation)}

Looking into Deardorff's work shows that by 'explicit attitudes' the author broadly understands, inter alia, a positive motivation for acting in intercultural situations, an appreciation for cultural diversity, a curiosity towards foreign people, and tolerance for ambiguity in new situations. Moreover, this definition clearly states, that intercultural competence can only be shown in intercultural situations. Consequently, this means, it only can be development in corresponding learning situations. The developed course should serve as such a situation.

Due to the fact, that the students, taking part in this course, were located in their home country during their course participation, we used AdobeConnect as main instructional resource for the course delivery ${ }^{4}$. AdobeConnect is a classical web conferencing tool, with which multiple users are enabled to perform online conferences. This means that all participants are at different places and meet in an online room for discussion and interaction. Using this software for educational settings works just in the same way. The tutor sends out a time for the meeting and a link for the online meeting room to all of his or her students. Everybody accesses the virtual meeting and with help of a webcam and a headset, everybody can interact with each other online, almost like in a physically existing room. For interaction processes the software offers tools like a whiteboard, a desktop sharing application, a chat area and many more. More details about how we used the software in the course were previously published e.g. in May et al. $(2015)^{5}$. Another important instructional resource was a remote laboratory, designed and implemented at the IUL at TU Dortmund University ${ }^{6-8}$. The remote laboratory offers the opportunity to perform tensile tests, a core experiment for manufacturing technology, from a distance. The physical existing experimentation equipment at the IUL can be accessed via Internet and results are displayed in a web-based graphical user interface. Using this technology the students can access the experiment and analyze the gained data from every place in the world, wherever there is a functioning Internet connection. Another option to use the system, and this is how we used it in context with our course, is to build up transnational distributed working groups, letting them work in teams with the equipment. Online collaboration tools for individual interaction besides from class meetings supplemented these tools (e.g. Skype, Facebook, etc.). The students chose these tools individually based on their individual preferences. With this combination we could deliver an online engineering class, which provides transnational interaction on different topics and at the same time practical engineering laboratories. In the following we will describe the course in more detail.

\section{Course description}

The course is based on two central concepts, both were inspiring and structuring for the general course design as well as for its inner structure. For the general course design Constructive Alignment, which is a fundamental concept for higher education design, was taken into account ${ }^{9}$. Within this concept the intended learning outcomes, the teaching and learning activi- 
ties, and finally the examination are in focus. Following the constructive alignment these three aspects of didactical design need to be aligned, meaning that they have to be designed with a close relation to each other. Even if this demand sounds quite easy, bringing it into practice can be challenging. Hence, a general course design process shifts within a triangle between these three components, equally taking into account each of them. Nevertheless, in many cases the design process begins with the intended learning outcomes, as they define what the students have to be able to do after a successful course completion. Based on the learning outcome, the activities and finally the respective examination can be designed. Two preliminary practical examples: For example, if the course's intended learning outcome is "Being able to perform experiments and with this to gain knowledge about material characteristics", there is no way around but letting the students do own experimentation. No oral lecture could provide a similar situation to gain these competences. The same is true for intercultural competence. If intercultural competence is seen as the practical ability to successfully act in intercultural situations, and if this is a course's intended learning outcome, the course activity is required to be an actual intercultural situation to act in. Just following a lecture about cultural diversity or specific country's cultural characteristics does not lead to the development of real intercultural competence. Furthermore, the examination has to be designed in a way so that it exactly measures these competences. This means that the examination must consist of situations in which the students are able to show these (possibly newly developed) competences. It does not make any sense to define intercultural competence as an intended learning outcome and to develop well-aligned learning activities with real intercultural interaction, and finally ask in a written exam for cultural characteristics of one explicit country. Such an exam only measures knowledge about intercultural aspects but not a intercultural competence based on real activity observation. However, in the following we will leave out the discussion about examination, as the course did not have any examination at the end.

The second inspiring concept is the learning spiral for intercultural competence, defined by D.K. Deardorff ${ }^{1}$. Based on this concept intercultural competence can be developed in four consecutive steps that can be understood as a circle, finally leading to spiral (see figure 2). Within the first step the learner's attitudes with regard to tolerance for ambiguity and appreciation for diversity are important. Based on these attitudes the learning process starts. In the second step the actual competence to act is focused. Within this context the aim is to gain cultural knowledge as well as the ability to communicate and to solve conflicts. This is followed by the third step, which aims at an internal effect on the learner's mindset, for example relativizing the own reference framework for thinking and acting. Deardorff calls this part: Competence to reflect. The last and final step aims at an external effect and the ability for constructive interaction in intercultural situations with others. This last step again has impact on the learner's attitudes and so the learning process results in a learning circle. Successfully going through this circle several times leads to the improvement of intercultural competence. This is why Deardorff talks about a learning spiral instead of a circle. For our course concept we took this spiral and designed learning activities that build up on one another, from cultural knowledge over self-reflection to intercultural interaction, and at the same time taking into account the constructive alignment. In the following the intended learning outcomes and the respective activities will be explained. 


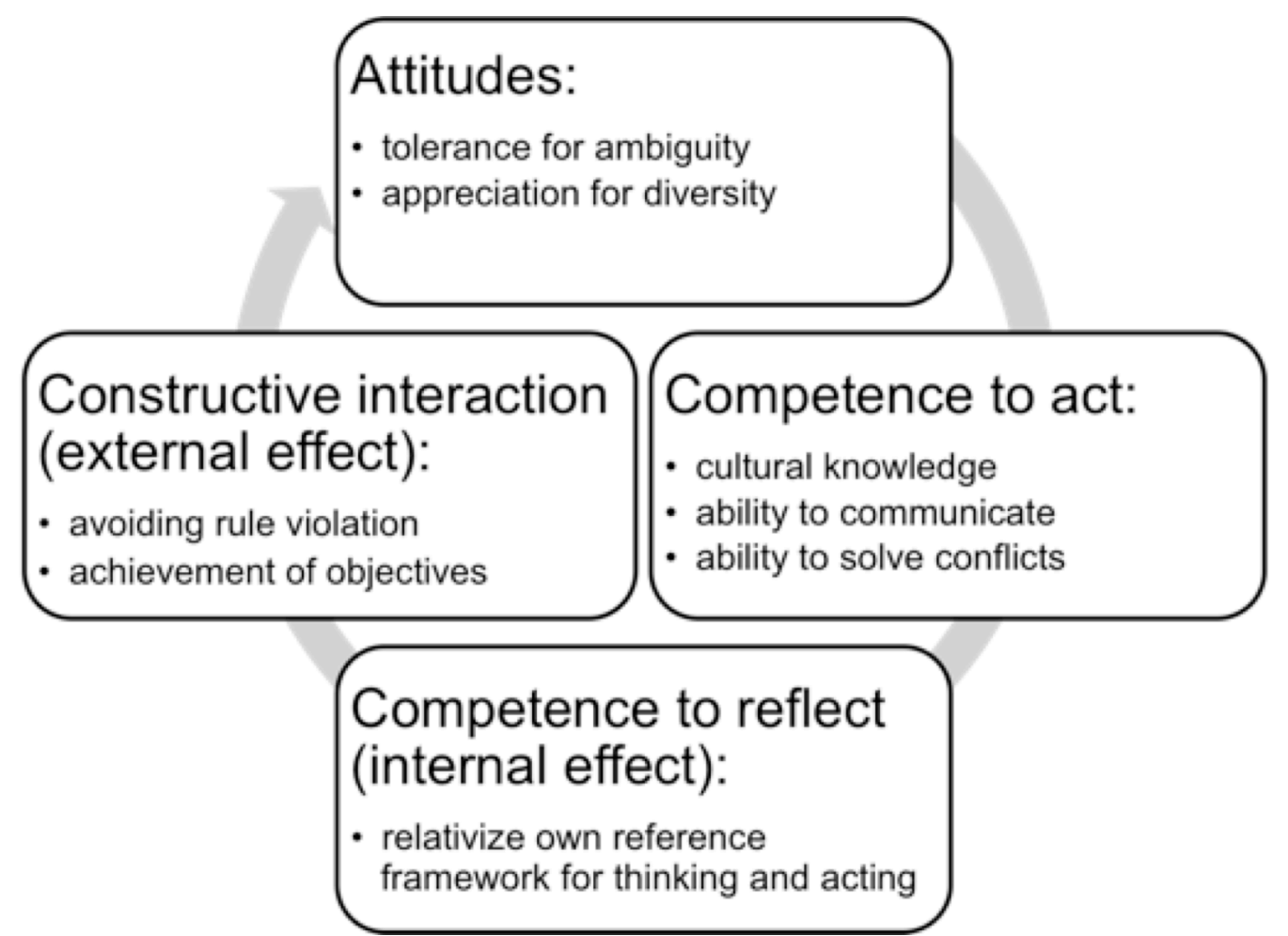

Figure 2: Circular model for intercultural competence development based on the work of Deardorff ${ }^{1}$

\section{Learning Outcomes}

In addition to the development of intercultural competence, another purpose was to bring the students into contact with their future surrounding culture and prospective classmates. Moreover, the fact that the course should prepare the students for an engineering master program profoundly affected the intended learning outcomes, too. Therefore, we included the remote experimentation process into the course. Additionally, in this context it seemed to be important to us to talk about technologies not only from a technical but also from varying nontechnical perspectives. Talking about technical as well as the cultural and organizational aspects of technology widens the students' view and deduces the opportunity to compare different perspectives on an intercultural level ${ }^{10}$. This approach subsequently leads back to development of intercultural competence.

All these considerations result to the following intended learning outcomes:

After the course the students should be able to...

1. ...describe their destination on basis of internet research

2. ...describe their own concept of engineering in comparison to others

3. ...reflect on international differences in engineering

4. ...use a basic model for describing technology from different perspectives (technical, cultural, organizational)

5. ...run experiments like the tensile test and use the gained data for engineering work by connecting theory and practice

6. ...explain a general stress-strain-diagram by identifying important points as well as explaining their relevance for forming technologies

7. ...communicate successfully with international engineering colleagues using internet technology 
8. $\quad$...organize themselves in a working process and work successfully together in multinational teams in order to fulfill explicit tasks

These learning outcomes can be divided into 4 different groups. Whereas the first outcome focuses on Dortmund and the students' destination, outcomes 2-4 express the necessity of being a reflective engineer who is able to put its own profession and work in context with other fields and finally in a global context. Outcomes 5 and 6 focus on central engineering aspects and define the objectives that are connected to the work with the laboratory equipment. Finally, outcomes 7 and 8 have to be seen in a broader context. They express the goals in context with international co-operation with the help of Internet technology. All of these intended outcomes were presented to the students during the first meeting, so that they knew what was expected from them during the upcoming course. Based on these intended learning outcomes the course activities are designed. They will be outlined in the following.

\section{Content and course activities}

Live online meetings were organized for the course and accompanied by group work to be done in-between these sessions. The online sessions were primarily dominated by presentations from the students, discussion groups or explanations by the lecturer in order to introduce a new topic or the next step in class. Even more important were the working phases between the live sessions. In these phases the students did own research on various topics or carried out preliminary work for the upcoming session. Therefore the whole student group was split into smaller working groups. The students were mixed so that every group was a blend of students from different countries with different cultural backgrounds. In these groups they worked on the given tasks, so that the students actually had to cooperate with each other making use of various Internet technologies. Based on the different topics and activities the course can be divided into three main parts:

- Local and cultural orientation

- Global orientation

- Technical orientation

These parts reflect the different intended learning outcomes. Figure 3 shows the course concept in an overview and its connection the model for intercultural competence development posed by Deardorff (see figure 2). The details will be explained in the following. 


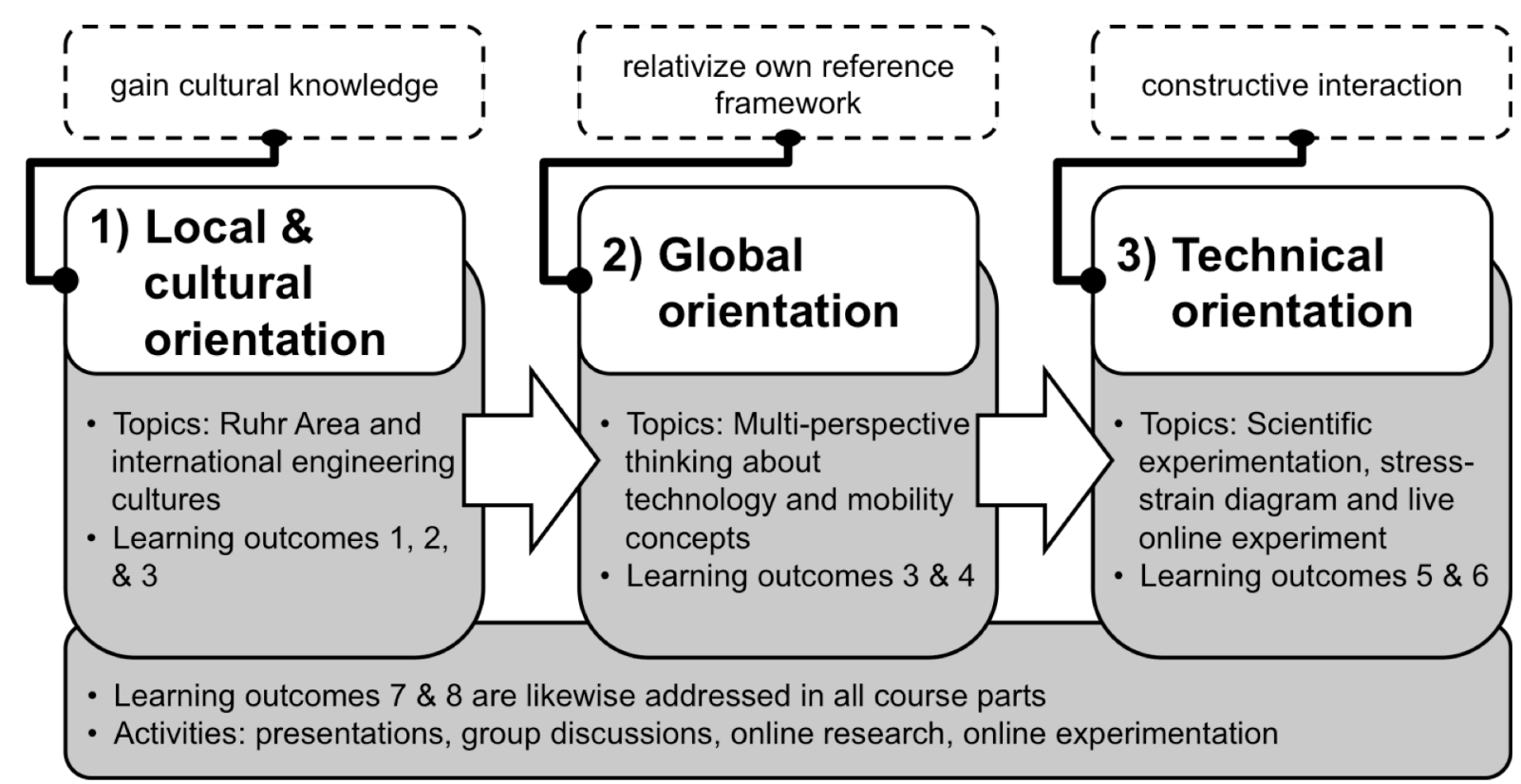

Figure 3: Course concept in three sequential parts and learning outcomes' allocation

The local and cultural orientation part addressed learning outcomes 1, 2, and 3. During this phase a special focus was put on the personal orientation in the course and the students' future destination. During this local orientation a short presentation about the Ruhr Area and its location within Germany, the city of Dortmund and the TU Dortmund University had to be given. This presentation was designed for the students to gain a broad overview over the area and enable them to start into a first working phase with basic knowledge. Divided into groups the students had to do an online research about their destination for their future master program, led by several questions to guide them. The first group had to find out more about regional information and the historical role of engineering in the Ruhr Area. A second group had to focus on current strengths in industry, science and research. And the third group concentrated on quality of life and future plans for the region. In addition to that, all of the groups were asked to compare their results with their home countries in terms of any major differences or even similarities. The results were presented and discussed in class during one of the early live sessions. Hereby the students simultaneously gained knowledge about their future destination and challenged their personal understanding about their own cultural background.

Furthermore, they were introduced into the home countries of their future classmates. Another activity in this course part was dominated by several discussions about the essence of the engineering profession, necessary competences for successful careers in engineering, and the general role of engineers within society of different countries and cultures. In this context we made use of the technical option offered by Adobe Connect to split the students into smaller groups and sent them to several breakout rooms for more intimate discussions. Some minutes later, they returned and shared the results of their discussion with the group as a whole.

Two different working phases were characterizing for the global orientation part, addressing learning outcome 3 and 4 . On the one hand the students had to work on a concept to describe technologies by having a closer look at not only technical but as well cultural and organizational aspects. Furthermore, they were told to develop a concept describing in how far and why technological progress and society development are two interlaced processes and determine one another. This activity was supported by out of class readings (see e.g. Neeley $(2010)^{10}$ or Pinch and Bijker $(1987)^{11}$ ) and by in-class discussions based on those readings. In 
this phase, the important aspect was to enable the students to discuss technology from different and even non-technical perspectives. From our point of view this is a necessity in order to develop intercultural competences, due to the assumption that pure technical understanding of technology is not sufficient for future engineers working in an international contexts. In a second step the students had to use the discussed models to prepare a presentation on different future mobility concepts from all over the world: The Land Airbus developed in China, the Personal Rapid Transit System used at Heathrow Airport in Great Britain and the Car Sharing system, which e.g. has been introduced in several bigger German cities. During this task the students again worked in smaller groups and did an in-depth research regarding one of these technologies. Based on that research and the previous readings, they had to create a presentation and answer questions like: "What are technical, organizational and cultural issues of that technology?", "What are relevant social groups that might have an interest in the technology or might have an impact on the technology's development?", or "Would that explicit technology be applicable for each of your home countries?". With this task the students were asked to think about their home country, make a statement regarding the compatibility of a technology for their country and compare that with their classmates' thoughts. These presentations led to interesting discussions comparing the same technology in different cultural contexts, e.g. concerning personal security aspects in public transport systems.

The technical orientation part addressed learning outcomes 5 and 6 . Here the remote laboratory comes into focus. In our course technical orientation is represented by the topic of vehicle design, or better, lightweight construction for vehicle design. Therefore the students (again in groups) had to do a tensile test with two different materials using the laboratory equipment at the IUL to gain knowledge about the explicit material properties. Afterwards these properties were used for working on the design tasks. Within this task the students had to design a safety-related component for a vehicle: Small pins, which prevent the engine from entering the passenger safety cell during a frontal crash. For designing those pins the students had to compare two material options (steel and aluminum). Therefore, the students remotely executed the experimentation with both materials using the IUL's testing cell. For the experimentation the students were free to do this whenever they were able to do it in their group. Hence, the working groups had to develop a working plan indicating when to do the experimentation and arrange the experimentation by booking an explicit timeslot for the used equipment. Based on the results the students had to work out a short report on the differences between the two materials and answer the question in how far the selected materials have impact on the production process.

Learning outcomes No. 7 and 8 cannot be assigned to one of the three course phases, as there is a continuous interaction between the participants. Especially during the working phases, in which the students have to do online research, prepare presentations or carry out experimentation, they learned a lot about international online collaboration.

\section{Participants in the two course editions}

In the 2014 edition of the course all in all 12 students from 10 different countries took part, speaking 10 different mother tongues (the students came e.g. from India, China, Pakistan, Nigeria, Brazil, Turkey, to name just a few). These different countries meant practical challenges for the course design as they the students lived in very different time zones. For the live online meetings it was necessary to split the participants into two groups right from start and deliver two identical courses for the two groups. One group consisted of participants from Far East countries (from Iran to China) and another group of the most western located 
participant from Brazil and students from the near east (Lebanon was the most eastern located country in this group). Even if it would have been beneficial to put all participants in a single group in order to have a more intercultural mixed group, we did not see any other option to face the time-zone problem. However, 11 of the course participants were male, one female. 7 of them were between 21 and 24 years old, whereas 5 of them were between 25 and 29. All of them either learned English during earlier education or because it is a second official language in their country.

In the 2015 course edition at the beginning 16 students ( 5 between 20 and 22, 7 between 23 and 25, 2 from 26-28 and 2 from 29-31) took part. Due to several reasons this number dropped to 14 participants during the course. The students came from 6 different countries: Mexico, Turkey, Iran, Pakistan, India, and Nepal. This distribution made it possible to realize one big single group in 2015.

\section{Concept for evaluation}

The 2014 course edition served as a proof of concept for the general course design. Based on the encouraging experiences and the positive feedback from the students, this first edition course was only slightly changed. For example we extended the number of live online meetings from 6 to 8 meetings. In addition to that a broad evaluation concept was designed and applied in 2015 in order to receive feedback for continuous improvement of future course editions. The evaluation concept focuses on different course aspects. Inter alia, the development of intercultural competence and the remote lab's integration into the course were examined using different evaluation approaches. In the following we will primarily concentrate on the general course feedback and the intercultural aspects.

Regarding the discussion on intercultural communication competence Chen's and Starosta's model received much attention ${ }^{12}$. Following this model intercultural communication competence consists of the three dimensions: intercultural awareness (cognitive dimension), intercultural adroitness (behavioral dimension) and intercultural sensitivity (affective dimension). For the latter Chen and Starosta additionally developed and introduced a measuring instrument, the Intercultural Sensitivity Scale (ISS) ${ }^{13}$. This scale basically is a questionnaire composed of 24 items with different statements. The statements are allocated to 5 different factors of intercultural sensitivity:

- Interaction engagement: Participants' feeling of participation in intercultural communication

- Respect for cultural differences: How participants orient to or tolerate their counterparts' culture ad opinion.

- Interaction confidence: Participants' confidence in intercultural settings.

- Interaction enjoyment: Participants' positive or negative reaction towards communicating with people from different cultures.

- Interaction attentiveness: Participants' effort to understand what is going on in intercultural interaction.

The model has been discussed, proved, questioned, shortened, and adapted to different cases and different nationalities ${ }^{14-17}$. However, we decided to work with the 24-item questionnaire as displayed in Fritz, Mollenberg and Chen (2002) ${ }^{14}$ without any changes as we considered the five factors as well as the used items to be suitable for our case, especially under consideration of Deardorff's model for the intercultural competence development, which has been the starting point for our work. Furthermore, this decision was taken because on the one hand 
the model and its possible improvement was not in our focus and on the other hand because of the small sample size we expected. Under these circumstances an extensive testing for the model's validity seemed to be neither appropriate nor necessary for our case. Hence, we decided to use the full model and work with these results. In order to actually use this scale for our course evaluation we took the questionnaire and performed a pre- and post-test, letting the students answer the same questions before and right after the course. The idea was to identify, if at least any changes would be detectable concerning the students' answers. The questions and their five accompanying factors can be retrieved from table 1.

Table 1: 24-item Intercultural Sensitivity Scale as used by Fritz, Mollenberg and Chen (2002) ${ }^{14}$ and based on the work by Chen and Starosta $(2000)^{13}$ (the indicated items were reverse coded before summing)

\begin{tabular}{|c|c|}
\hline \multicolumn{2}{|c|}{$\begin{array}{l}\text { Task: Below is a series of statements concerning intercultural communication. There } \\
\text { are no right or wrong answers. Please work quickly and record your first impression } \\
\text { by indicating the degree to which you agree or disagree with the statement. } \\
\text { (1="strongly disagree"; } 2=\text { "disagree"; } 3=\text { "uncertain"; } 4=" \text { agree"; } 5=" \text { "strongly agree") }\end{array}$} \\
\hline \multicolumn{2}{|c|}{ Factor: Interaction engagement } \\
\hline $\begin{array}{l}\text { Item No. } \\
24\end{array}$ & $\begin{array}{l}\text { I have a feeling of enjoyment towards differences between my culturally distinct } \\
\text { counterpart and me. }\end{array}$ \\
\hline 22 & $\begin{array}{l}\text { I avoid those situations where I will have to deal with culturally-distinct persons. } \\
\text { (reverse coded) }\end{array}$ \\
\hline 1 & I enjoy interacting with people from different cultures. \\
\hline 11 & I tend to wait before forming an impression of culturally-distinct counterparts. \\
\hline 21 & $\begin{array}{l}\text { I often give positive responses to my culturally different counterpart during our } \\
\text { interaction. }\end{array}$ \\
\hline 23 & $\begin{array}{l}\text { I often show my culturally-distinct counterpart my understanding through verbal } \\
\text { or nonverbal cues. }\end{array}$ \\
\hline 13 & I am open-minded to people from different cultures. \\
\hline \multicolumn{2}{|c|}{ Factor: Respect for cultural differences } \\
\hline 16 & I respect the ways people from different cultures behave. \\
\hline 8 & I respect the values of people from different cultures. \\
\hline 18 & $\begin{array}{l}\text { I would not accept the opinions of people from different cultures. (reverse cod- } \\
\text { ed) }\end{array}$ \\
\hline 2 & I think people from other cultures are narrow-minded. (reverse coded) \\
\hline 7 & I don't like to be with people from different cultures. (reverse coded) \\
\hline 20 & I think my culture is better than other cultures. (reverse coded) \\
\hline \multicolumn{2}{|c|}{ Factor: Interaction confidence } \\
\hline 3 & I am pretty sure of myself in interacting with people from different cultures. \\
\hline 10 & I feel confident when interacting with people from different cultures. \\
\hline 5 & I always know what to say when interacting with people from different cultures. \\
\hline 4 & $\begin{array}{l}\text { I find it very hard to talk in front of people from different cultures. (reverse cod- } \\
\text { ed) }\end{array}$ \\
\hline 6 & $\begin{array}{l}\text { I can be as sociable as I want to be when interacting with people from different } \\
\text { cultures. }\end{array}$ \\
\hline \multicolumn{2}{|c|}{ Factor: Interaction enjoyment } \\
\hline 12 & $\begin{array}{l}\text { I often get discouraged when I am with people from different cultures. (reverse } \\
\text { coded) }\end{array}$ \\
\hline 9 & $\begin{array}{l}\text { I get upset easily when interacting with people from different cultures. (reverse } \\
\text { coded) }\end{array}$ \\
\hline
\end{tabular}




\begin{tabular}{|c|c|}
\hline 15 & $\begin{array}{l}\text { I often feel useless when interacting with people from different cultures. (reverse } \\
\text { coded) }\end{array}$ \\
\hline \multicolumn{2}{|c|}{ Factor: Interaction attentiveness } \\
\hline 14 & I am very observant when interacting with people from different cultures. \\
\hline 17 & $\begin{array}{l}\text { I try to obtain as much information as I can when interacting with people from } \\
\text { different cultures }\end{array}$ \\
\hline 19 & $\begin{array}{l}\text { I am sensitive to my culturally-distinct counterpart's subtle meanings during our } \\
\text { interaction. }\end{array}$ \\
\hline
\end{tabular}

In addition to ISS we decided to ask some supplementary questions, which were formulated more closely to the actual learning outcomes and activities. Within these questions, global engineering practice and the student's perception towards it was focused. The questions base on the work by Wold (2014) $)^{18}$, who already successfully used them for course evaluation ${ }^{19}$. Just like the ISS these questions were used in form of a pre- and post-test in order to detect possible changes. The additional questions can be seen in table 2 .

Table 2: Additional questions in context with global engineering practice following Wold (2014) ${ }^{18}($ the indicated items were reverse coded before summing)

\begin{tabular}{|c|c|}
\hline \multicolumn{2}{|c|}{$\begin{array}{l}\text { Task: Below is a series of statements concerning engineering and international connec- } \\
\text { tions. There are no right or wrong answers. Please work quickly and record your first } \\
\text { impression by indicating the degree to which you agree or disagree with the state- } \\
\text { ments. (1="strongly disagree"; } 2=\text { "disagree"; } 3=" \text { uncertain"; } 4=\text { "agree"; } 5=" \text { strongly } \\
\text { agree") }\end{array}$} \\
\hline $\begin{array}{l}\text { Item } \\
\text { A }\end{array}$ & $\begin{array}{l}\text { Engineering solutions are independent of local cultural practices. (reverse cod- } \\
\text { ed) }\end{array}$ \\
\hline $\begin{array}{l}\text { Item } \\
\text { B }\end{array}$ & $\begin{array}{l}\text { Engineering solutions can be transferred from one national context to another } \\
\text { without applying any changes. (reverse coded) }\end{array}$ \\
\hline $\begin{array}{l}\text { Item } \\
\text { C }\end{array}$ & $\begin{array}{l}\text { The most important aspect of engineering solutions is their technical part. (re- } \\
\text { verse coded) }\end{array}$ \\
\hline $\begin{array}{l}\text { Item } \\
\text { D }\end{array}$ & $\begin{array}{l}\text { Engineers all over the world are working in the same way and their work is } \\
\text { based on the same principles as well as methods. (reverse coded) }\end{array}$ \\
\hline $\begin{array}{l}\text { Item } \\
\text { E }\end{array}$ & $\begin{array}{l}\text { It is important for engineers to know about engineering practices used by engi- } \\
\text { neers from other countries. }\end{array}$ \\
\hline $\begin{array}{l}\text { Item } \\
\text { F }\end{array}$ & $\begin{array}{l}\text { It is important for engineers to learn how to work in teams with engineers from } \\
\text { other cultures. }\end{array}$ \\
\hline $\begin{array}{l}\text { Item } \\
\text { G }\end{array}$ & $\begin{array}{l}\text { It is important for engineers to learn how to work in teams with colleagues from } \\
\text { other disciplines. }\end{array}$ \\
\hline
\end{tabular}

Looking at the students' individual feedback to the course and their personal perceived competence development rounded up the concept for evaluation. These feedback questions and the students' answers are shown at the corresponding place in the following chapter, discussing the results. 


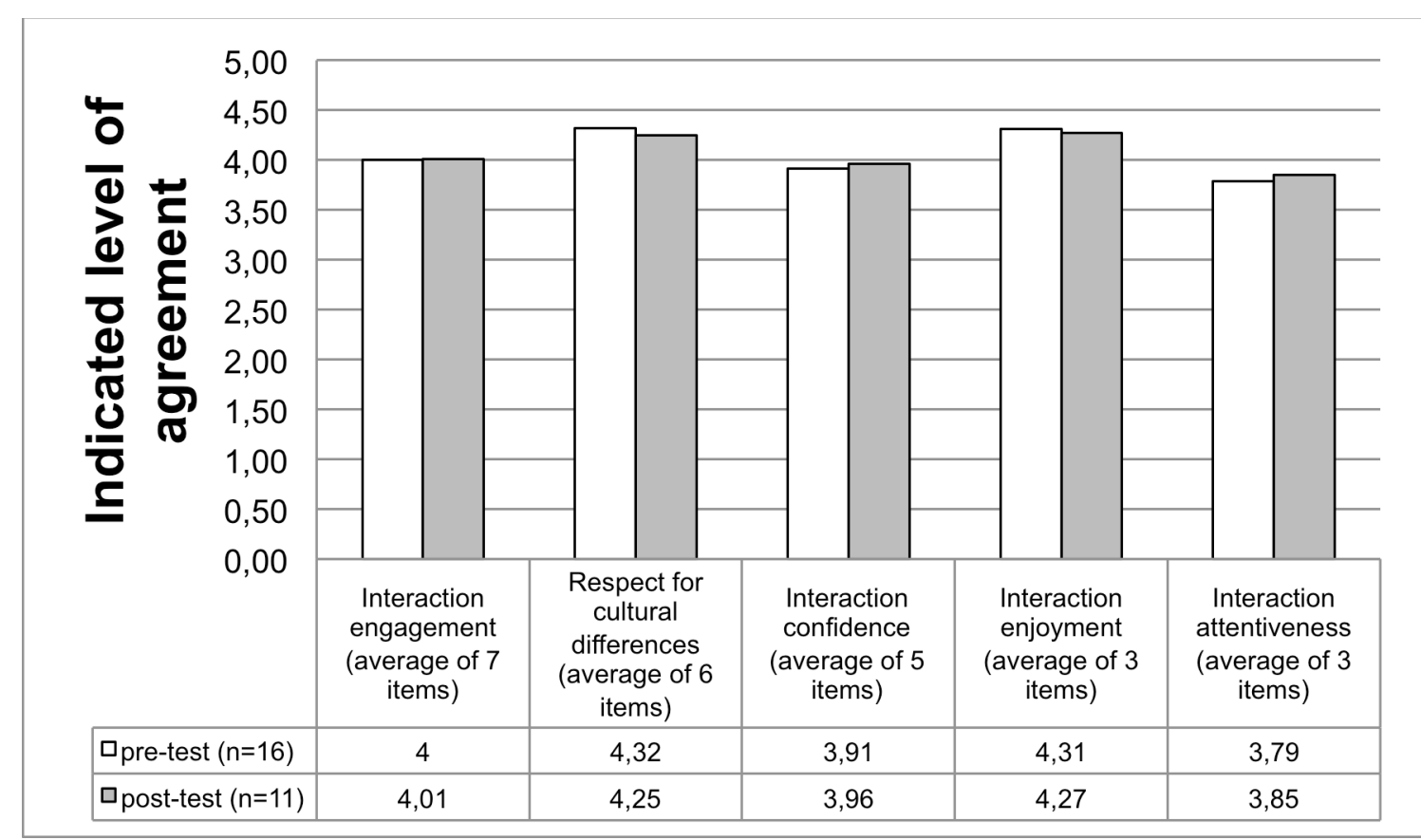

Figure 4: Average student scores during pre-and post-test in Intercultural Sensitivity Scale

\section{Evaluation Results}

In the following the evaluation results developed with the above shown concept will be displayed. These results refer to the 2015 course edition only. Figure 4 shows the evaluation results gained with the help of the ISS. The data show the average from the students' answers during the pre- and post-test concerning five different factors of intercultural communication competence. A very apparent result based on the data is that the students on an average start from a pretty high level, as the average is close to or in most cases even above a score of 4 . In comparison to that and speaking about a competence development, it must be admitted, that even if there is a slight increase concerning three of the factors, a significant change could not be proven. In fact for two of five factors, there even is a slight decline. This would mean that the students lost competence through the course participation. Assuming that this is hardly possible, other explanations might be discussed. Because of the comparatively small number of participating students and the small " $n$ " resulting from this fact, we waived at this point the option to do more in-depth statistical analysis, e.g. to run a reliability analysis or to compare the student groups from the pre-test to the post-test. Even if the 11 students participating in the post-test are out of the group from the pre-test, due to anonymity reasons we cannot make any assumption about internal group constellations impacting the results. In addition to that, another effect might be seen in the data: Kruger and Dunning $(1999)^{20}$, Dunning at al. $(2003)^{21}$, and Krajc and Ortmann (2008) ${ }^{22}$ report about the students' tendency to overestimate their competence before an educational intervention in context with self-assessment. In such cases experiencing the intervention can lead to more realistic self-assessment scores. In this case it could mean, that the students taking part in the course and not being very used to real intercultural situations overestimated their ability to act in such situations at the beginning. During the course they might have firstly leveled their perceived competence level and based on that secondly improved their competence level. This might lead to more realistic but not higher scores at the end of the course. Such a development would not be visible in the data and it would need other evaluation methods like individual interviews. However, until now 
these are only assumptions on the effects that might be visible in the data. For now this issue remains unexplained but further research will be taken out on that question.

In addition to the ISS questions we asked the students in the post-test, if they thought that their answers might have changed caused by course participation. The answers on this question are interesting, as 8 of the 11 participants actually reported that their answers changed. The following statements will be given as examples in order to display the students' thoughts:

- Student A: "I think they are same. I had already experienced working with people from different culture. I was able to apply that experience and improve my skills."

- Student B: "Somehow. I got a more realistic view towards my feelings to this issue."

- Student C: "Yes, my answers have changed by a fair amount. I was a little tensed before about talking to people from my neighboring countries. It is simply because of tension in Indian subcontinent and we people from north India are a little scared of entire thing. But, after the course I got to know people from my neighboring countries and I was glad to have interaction with them."

- Student D: "It has changed so far I think. I am very much confident than I used to be while interacting with people from other culture. Now I enjoy it."

- Student E: "This was the first time I was interacting with so many people from different cultures. I was able to interact easily and it was a wonderful experience."

Even if the first statement does not indicate to changed answers, student A actually does report an improvement of his own skills, which can be seen as a positive feedback for the course. The answer of student B is even more interesting, as it underlines one of our above made assumptions. It is a positive result for us, if the course leads to more realistic views on the students' self-perception towards their own competences acting in intercultural situations. Student C, D, and E also report, that their answers have changed. Summing up, the results from this individual feedback are even more interesting for us than the Scale results and they are much more expressive and supportive for our work. With this we will change over to the results on the questions on engineering and international connections. Figure 5 displays the average level of agreement to each of the posed questions.

Looking at the data it becomes obvious that for almost every item (except for E) the average score improved between the pre- and the post-test. Even if the increase in some of the scores is again rather small, the image drawn by the data is much more differentiated than in the aforementioned results. Especially item $C$ and D show a clear increase. Based on the experiences regarding individual feedback, we will directly change over to the feedback we received in context with these questions. Just like before, we asked the students if they think that their answers might have changed during course participation. In the following we show six exemplary answers:

- Student A: "Yes they have definitely changed. They have changed technically and socially, as there was interaction with students from different society having different experiences."

- Student B: "Yes. I did not know how much a culture could affect technical and engineering issues."

- Student C: "Yes. Getting familiar with other cultures and different ideology made this changes in my opinion.” 


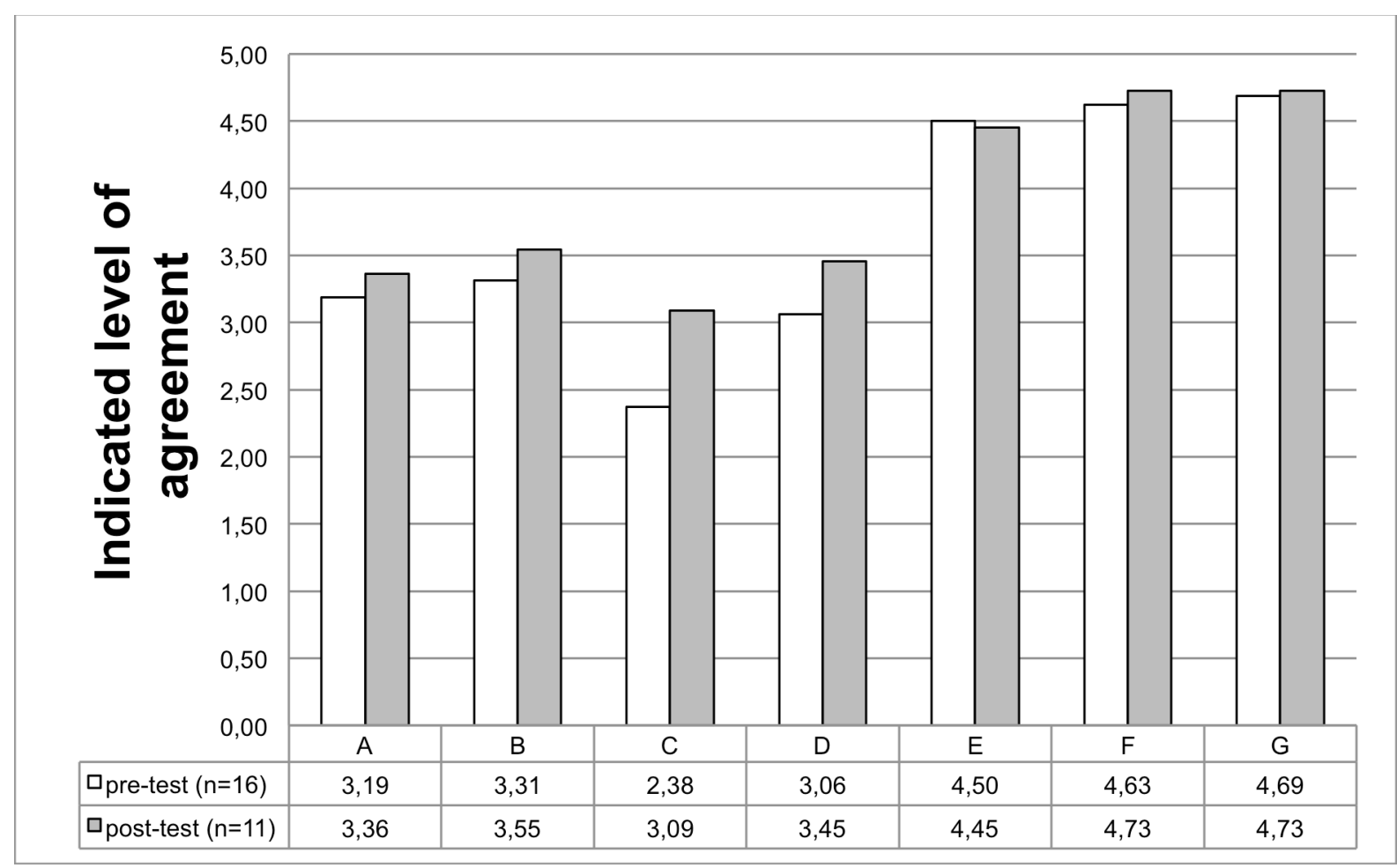

Figure 5: Average pre- and post-test results concerning engineering and international connections

- Student D: "I think they have changed. After meeting people from different cultural background, I understand now better the factors go hand in hand with engineering problems."

- Student E: "Yes, my answers have changed because I did not know the level of importance of cultural aspect at the beginning of the course."

- Student F: "Yes, my answers to these questions have changed a little bit. This pre course broadened my vision."

Looking at these answers supports the positive impression from the data shown in figure 5. All 11 students reported that their answers have changed caused by the course participation. The individual statements underline that, interacting with students from different cultural backgrounds and the discussion about technology helped them to understand how social as well as cultural aspects can affect engineering work. From most of these statements it can be deduced that mainly the second activity, in which we discussed different mobility concepts from different local perspectives, had an impact on the students' thoughts. Hence, we see it to be very fruitful to put students into situations, in which they have to notionally apply technologies to their own local community and compare their thoughts with students from other cultural backgrounds. Comparing the different perceptions can lead to a better understanding of the own and the others' perspective. Achieving this would mean to reach an important aim in context with intercultural competence development. Finally, we understand the last comment from student $\mathrm{F}$ very supportive for the course concept and our work in general. If we are able to use online learning formats to enhance the collaboration between international students and thereby "broaden their horizons" about the world in general and/or the engineering practice in particular, there is not much more we can hope for with such course concepts. 


\section{Summary and future work}

This paper presents an online course for international mechanical engineering students, which was introduced in 2014 and had been carried out a second time in late summer 2015. Two perspectives inspire the course's educational concept. On the one hand it is designed to prepare students for their future period of studies in an international master degree program at a German university. As the students, who sign up for this master program, come from all over the world, they all have differing cultural background and are used to different educational systems. Hence, the course's intention is to bring them into contact with the German culture and the educational system they will be facing later on. Additionally they are enabled to come into contact with their future classmates at a very early stage. On the other hand the course is designed to enable the students in general to work effectively in international teams, which can be seen as one of the future core competence for engineers needed in professional contexts, either at scientific institutions or in industry. This requires that the students develop practice based intercultural competences in real intercultural situations during their studies. The presented course offers such an opportunity in an online environment. As the course is fully taught online, students can stay in their home country while course participation. Using AdobeConnect as an instructional resource opens up the opportunity to run live online class sessions just as in a real classroom. That means that the participating students are present "only" via Internet but work together in a transnational environment. During the course the students work in culturally mixed international teams, answer questions about their prospective destination or future mobility concepts for big cities and make use of remote laboratory equipment for basic engineering experimentation. The remote experimentation is one of the core activities during the course and with this the presented course is an example for a course design that aims at both intercultural as well technical competence development as equal course objectives.

For the 2015 course edition an evaluation concept had been designed and applied, in order to ascertain if and in how far the course participation impacts the student's intercultural competence. For this purpose the ISS, developed by Chen and Starosta, had been adopted and used in form of a pre- and post-test approach before and after course participation. The questions in the concept have been supplemented by additional questions concerning international engineering practice. Frankly speaking, the results gained through these two questionnaires are not very overwhelming. Especially the results of the ISS don't show a significant development between the first and the second point of measurement. Possible reasons for that can only be assumed so far. In addition to the possible reason that the students simply overestimated their personal competences before the course and assessed their personal competence level more precisely, it might have been the case that using this instrument for such a small number of participants and for a rather short 4-week online intervention was like using a sledgehammer to crack a nut. Hence, there will be done several adjustments regarding the questionnaires for future course editions and evaluation. Better results have been gained through the questions on international engineering practice. Here almost in every question the students reported a higher level of understanding for the importance to understand technology not only from a technical but also from non-technical perspectives. Based on this, they are more likely in the position to show the ability to work effectively in international engineering contexts. This is strongly supported by the individual student feedback. Hence, we will partly step back from a quantitative and questionnaire based evaluation and we will focus more on qualitative methods using open instead of closed questions. This will help to get more useful information about the students' competence development during the course. Nevertheless, expanding such online course concepts for transnational interaction will results in the necessi- 
ty to also apply quantitative methods for evaluation. Even if the example presented here clearly shows problems in context with the evaluation results' interpretation, whether because of the short course time or the small number of participants, we gained valuable experiences in working with the applied questionnaires.

However, the general course feedback by the students was very positive. All of them reported that they really did appreciate to take part in this course and to start working together online via the Internet, which was a new experience for most of them. Asked for the course highlights the students primarily named the online experimentation part. In addition to that they did like do research on TU Dortmund University in order to orient themselves in their future destination. Summing up, we made very positive experiences with the course and the students' participation, so that the basic concept will be maintained for the near future.

A third edition will be carried out in summer 2016 and adjustments will be made in the 2015 experiences and the evaluation results. Moreover, another task for the future will be the evaluation concept's development. With this we are hoping to get even more in-depth results on the students' competence progress and use that in turn for the course improvement. Either way, we see such online approaches very promising for building transnational learning communities in engineering education. Especially the combination of such online delivered courses and the use of remote laboratories will be in focus for our future work. In times of a still increasing globalization in industry, the educational sector should seek, regardless of the options to study abroad, for alternatives to integrate intercultural competence development in the general curricula. This aim of course should not be achieved at the expense of the technical work in engineering education. With our approach we are able reach both. On the one hand the students are able to practice working in transnational teams and at the same time they can do core engineering work by doing technical experimentation. This is why we value this approach as a very promising one and will therefore expand transnational online education in our contexts using similar approaches.

1. BertelsmannStiftung, "Interkulturelle Kompetenz - Schlüsselkompetenz des 21. Jahrhunderts?", Gütersloh, 2006

2. Statistisches Bundesamt. Anzahl der ausländischen Studierenden an Hochschulen in Deutschland in den Wintersemestern 2013/2014 und 2014/2015 nach Herkunftsländern. http:/de.statista.com/statistik/daten/studie/301225/umfrage/auslaendische-studierende-in-deutschland-nachherkunftslaendern/ (zugegriffen am 18. Januar 2016).

3. Statistisches Bundesamt. Anzahl der deutschen Studierenden im Ausland von 2003 bis 2013. http://de.statista.com/statistik/daten/studie/167053/umfrage/deutsche-studierende-im-ausland/ (zugegriffen am 18. Januar 2016).

4. http://www.adobe.com/de/products/adobeconnect.html, last check on 01/18/2016

5. May, D., A. Sadiki, C. Pleul \& A. E. Tekkaya (2015): "Teaching and learning globally connected - Using live online classes for preparing international engineering students for transnational collaboration and for studying in Germany"; in proceedings of International Conference on Remote Engineering and Virtual Instrumentation (REV 2015); Bangkok, Thailand; February 25th-28th, 2015; 114-122

6. C. Terkowsky, I. Jahnke, C. Pleul, D. May, T. Jungmann \& A. E. Tekkaya, PeTEX@Work. Designing CSCL@Work for Online Engineering Education, In: S. P. Goggins, Isa Jahnke \& V. Wulf (Eds.) "Computer-Supported Collaborative Learning at the Workplace - CSCL@Work" Springer, ComputerSupported Collaborative Learning Series, Vol. 14, 2013, pp. 269-292

7. C. Terkowsky, I. Jahnke, C. Pleul, R. Licari, P. Johannssen, G. Buffa, M. Heiner, L. Fratini, E. Lo Valvo, M. Nicolescu, J. Wildt \& A.E. Tekkaya, (2010) "Developing Tele-Operated Laboratories for Manufacturing 
Engineering Education. Platform for E-Learning and Telemetric Experimentation (PeTEX)," in: International Journal of Online Engineering (iJOE), Vol.6 Special Issue 1: REV2010, Vienna, IAOE, pp. 60-70. DOI: 10.3991/ijoe.v6s1.1378

8. Ortelt, T. R.; Sadiki, A.; Pleul, C.; Becker, C.; Chatti, S.; Tekkaya, A. E.: "Development of a TeleOperative Testing Cell as a Remote Lab for Material Characterization". International Conference on Interactive Collaborative Learning (ICL), 2014

9. J. B. Biggs and C. Tang, "Teaching for quality learning at university. What the student does", 3rd ed., Maidenhead: McGraw-Hill, 2007, p. 50 and following

10. Kathryn A. Neeley, "Toward an Integrated View of Technology”, In K.A. Neeley (Ed.) Technology and Democracy - A Sociotechnical System Approach, Cognella, San Diego (USA), 2010, pp. 37-45

11. T.J. Pinch and W. E. Bijker, "The social construction of Facts and artifacts: Or how the sociology of science and the sociology of technology might benefit each other" In W. E. Bijker, T. P. Hughes and T. J. Pinch (Eds.), The Social Construction of Technological Systems: New Directions in the Sociology and History of Technology (pp. 17 - 50). Cambridge, Massachusetts: The MIT Press, 1987

12. Chen, G. M., \& Starosta, W. J. (1996): Intercultural communication competence: a synthesis. Communication Yearbook, 19, 353-383.

13. Chen, G. M., \& Starosta, W. J. (2000): The development and validation of the intercultural communication sensitivity scale. Human Communication, 3, 1-15

14. Fritz, W., Mollenberg, A., \& Chen, G. M. (2002). Measuring Intercultural Sensitivity in Different Cultural Contexts. Intercultural Communication Studies, 11(2), 165-176.

15. Fritz, W., Graf, A., Hentze, J., Mollenberg, A., \& Chen, G. M. (2005). An examination of Chen and Starosta's Model of Intercultural Sensitivity in Germany and United States. Intercultural Communication Studies, 14(1), 53-64

16. Tamam, Ezhar (2010) Examining Chen and Starosta's model of intercultural sensitivity in a multiracial collectivistic country. Journal of Intercultural Communication Research, 39 (3). pp. 173-183.

17. Wu, Jia-Fen (2015) Examining Chen and Starosta's Model of Intercultural Sensitivity in the Taiwanese Cultural Context, I.J. Modern Education and Computer Science, 2015, 6, 1-8

18. Wold, Kari (2013) Evaluating the impact of role-playing simulations on global competency in an online transnational engineering course, Dissertation at the University of Virginia, ProQuest Dissertations And Theses; Thesis (Ph.D.)--University of Virginia, 2013.; Publication Number: AAT 3573531

19. May, D., Wold, K., \& Moore, S. (2014). Using interactive online role-playing simulations to develop global competency and to prepare engineering students for a globalized world. European Journal of Engineering Education, Taylor\&Francis

20. J. Kruger \& D. Dunning (1999): "Unskilled and unaware of it: How difficulties in recognizing one's own incompetence lead to inflated self-assessments"; Journal of Personality and Social Psychology; 77(6); pp. 1121-1134

21. D. Dunning, K. Johnson, J. Ehrlinger \& J. Kruger (2003): "Why people fail to recognize their own incompetence"; Current Directions in Psychological Science; 12(3); pp. 83-87

22. M. Krajc \& A. Ortmann (2008): "Are the unskilled really that unaware? An alternative explanation"; Journal of Economic Psychology; 29(5); pp. 724-738 